\title{
In vivo and in vitro Development of Human Mesencephalic Dopaminergic Neurons
}

\author{
Vincenzo Silani, Donatella Mariani, Franca M. Donato, Franca Mazzucchelli, \\ Mauro Buscaglia*, Giorgio Pardi* and Guglielmo Scarlato \\ "Dino Ferrari" Center - Institutes of Neurology and *Obstetrics and Gynecology of the \\ University of Milan Medical School, Via F. Sforza 35, 1-20122 Milan, Italy
}

Development of mesencephalic dopaminergic cells is well characterized in rodents and partially defined in primates. In the human fetus, tyrosine hydroxylase (TH) immunoreactivity was first observed at 7 weeks of gestation.

Migration and neuritic elongation of $\mathrm{TH}^{+}$ cells were monitored from 7 to 12 weeks of gestational age. Intact fetal mesencephalon was post-fixed and sections obtained to demonstrate dopaminergic cell anatomical location. At 8 weeks, $\mathrm{TH}^{+}$neurons were found in a crescentic band occupying the middle third of the ventral mesencephalon. $\mathrm{TH}^{+}$cell migration was confirmed in the medial third of the ventral mesencephalon at 9 weeks and by 11 weeks a large number of dopaminergic cells had elaborated neural processes. These data complement the observations of Freeman et al. /3/ that similarly described early dopaminergic cellular development.

Growth potentialities of the dopaminergic cells were evaluated in primary cultures. Neuronal cells were identified for non-specific markers (Neuron Specific Enolase). $\mathrm{TH}^{+}$cells represented 1 to $2.5 \%$ of the total neuronal population, strictly dependent on precise dissection. One peculiar feature of $\mathrm{TH}^{+}$neurons is the formation of long neurite (axons) projections in the presence and absence of the co-cultured striatal-specific target. Treatment of these cultures with fibroblast growth factors (FGF) significantly increased the number of surviving $\mathrm{TH}^{+}$neurons at $8 \mathrm{~d}$ in vitro and induced proliferation of glial cells. Dopaminergic cells showed specific tropism for astroglial GFAP + cells. Previous studies demonstrated that mesencephalic glia specifically support the survival of dopamin- ergic neurons and induce dendritic outgrowth $12,4 /$. Some of the GFAP+ cells were shown to express NGF-low affinity receptors (NGF-R) on the membrane surface. NGF-R were identified with double staining for GFAP and NGF-R, using a confocal microscopy technique (monoclonal antibody against NGF-R obtained from clone ME 20-4 and 8211).

$\mathrm{TH}$, the rate-limiting enzyme in the biosynthesis of catecholamines, was biochemically assayed as a quantitative index of dopaminergic cell number and viability. Enzymatic activity was determined using the $\mathrm{TH}$ microassay described by Bostwick et al. /1/. This microradiometric assay can detect the production of $5 \mathrm{pmol}$ of ${ }^{14} \mathrm{CO}_{2}$ (coupled non-enzymatic decarboxylation of Dopa). $10^{5}$ cells were plated in a 96 microwell plate and the TH activity assayed at days 6 to 10 . Linearity of the $\mathrm{TH}$ enzyme reaction with time and protein concentration was demonstrated. TH activity was shown to increase by culture day 6 and then to decline.

Characterization of developmental events in the human mesencephalic dopaminergic neurons provides significant pre-clinical information to define the optimal age characteristics for brain grafting. Percentage of dopaminergic neurons and number of proliferating glial cells may be controlled after precise anatomical dissection. A TH microassay was applied to the human dopaminergic cells in vitro and FGF was shown to affect $\mathrm{TH}^{+}$neuronal cell development. Further investigations on glial-mediated processes in the human nigra are necessary to define the direct/indirect effects of FGF on dopaminergic neurons. 


\section{REFERENCES}

1. Bostwick RJ, Le WD. A tyrosine hydroxylase assay in microwells using coupled nonenzymatic decarboxylation of Dopa. Anal Biochem 1991; 192: 125-130.

2. Chamak B, Fellows A, Glowinski J, Prochiantz A MAP2 expression and neuritic outgrowth and branching are coregulated through region-specific neuro-astroglial interactions. J Neurosci 1987; 7: 3163-3170.
3. Freeman TB, Spence MS, Boss BD, Spector $\mathrm{DH}$, Strecker RE, Olanow CW, Kordower JH. Development of dopaminergic neurons in the human substantia nigra. Exp Neurol 1991; 112: 344-353.

4. O'Malley EK, Black IB, Dreyfus CF. Dopaminergic cell number is selectively increased by substantia nigra support cells in vitro. Soc Neurosci Abstr 1989; 15: 1260 . 

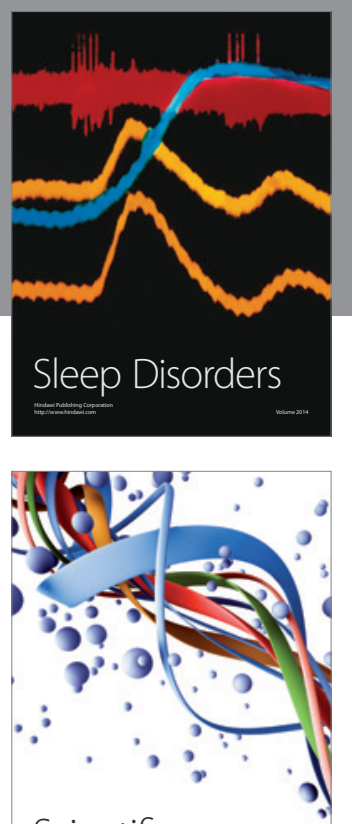

Scientifica
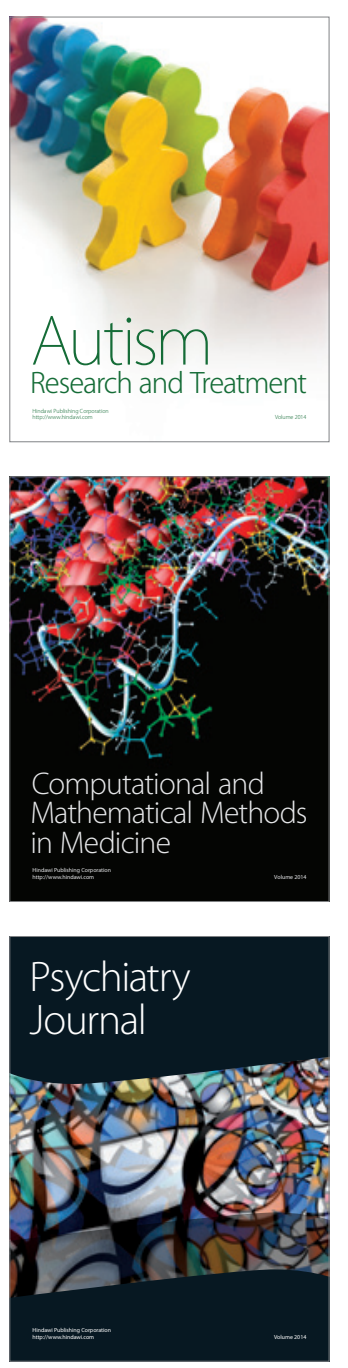
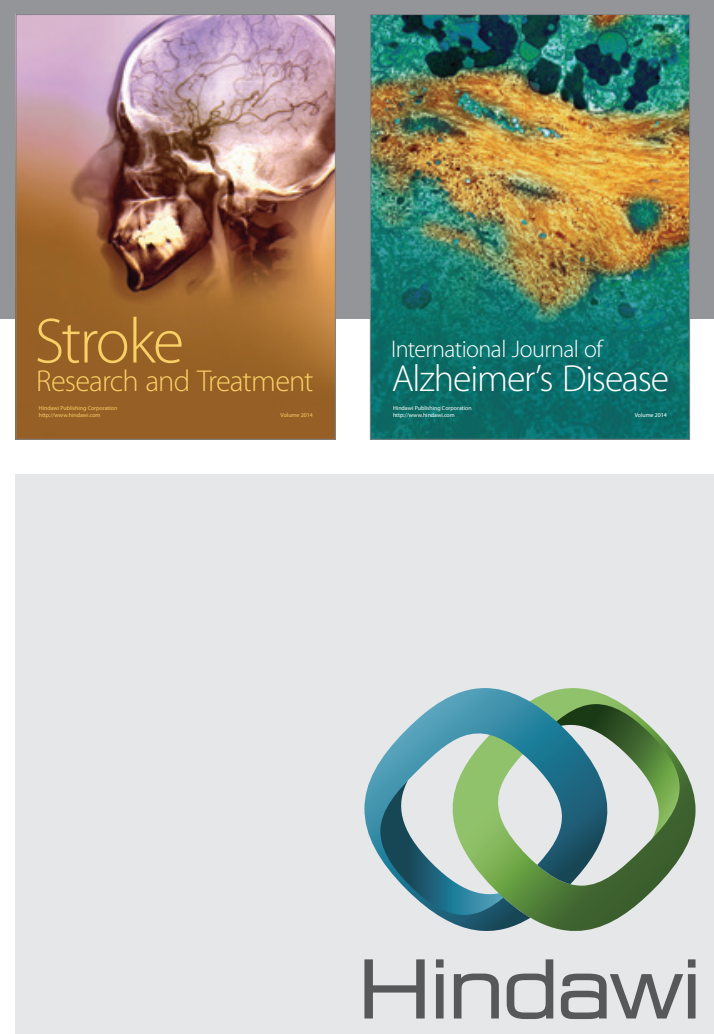

Submit your manuscripts at

http://www.hindawi.com
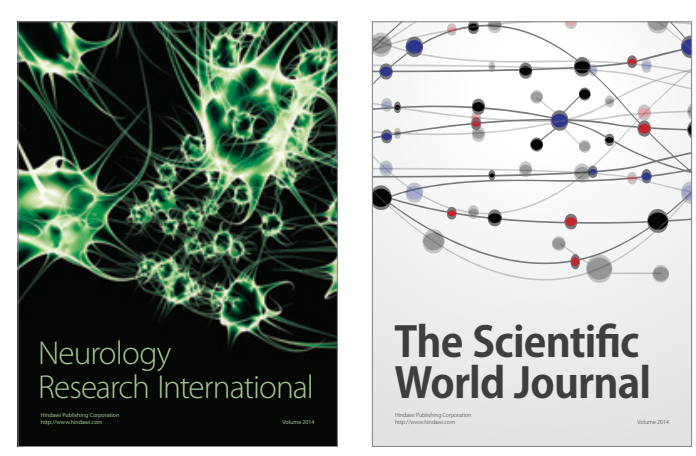

The Scientific World Journal

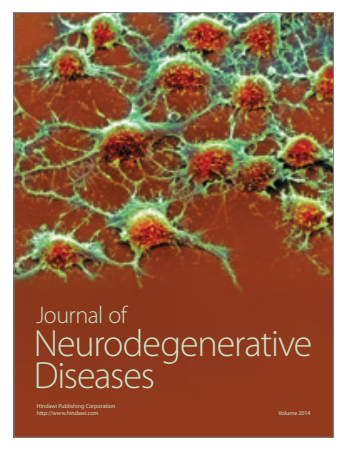

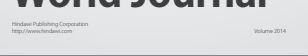

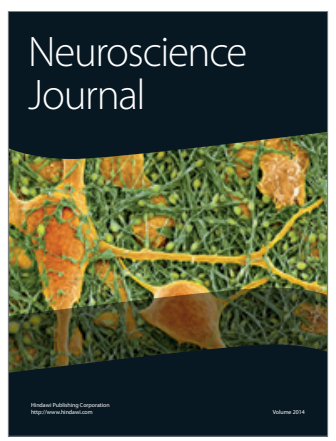

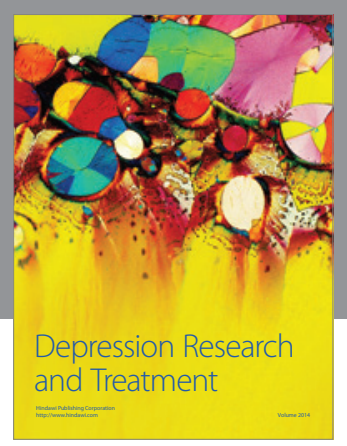
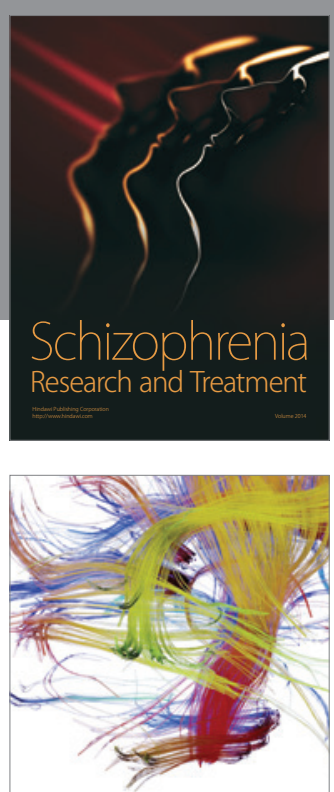

Brain Science

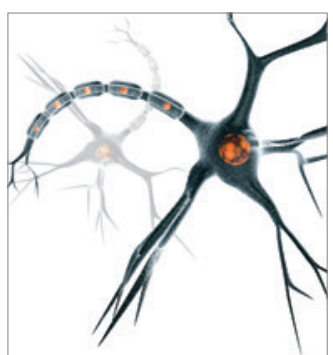

Neural Plasticity
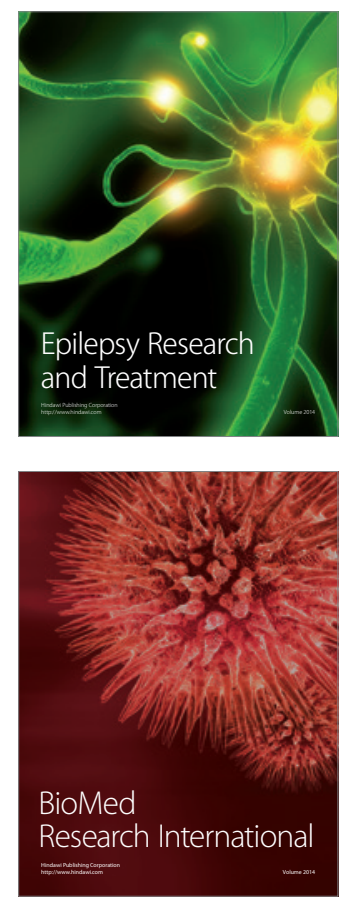

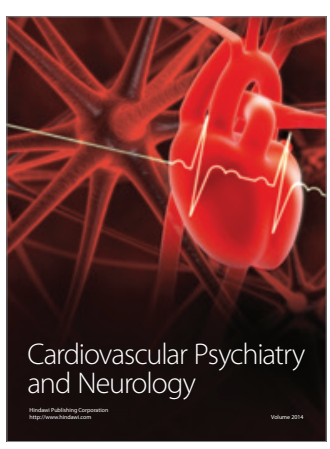

Parkinson's

Disease
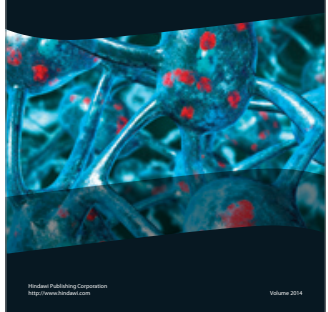